\title{
Preparation of Polyethersulfone Ultrafiltration Tubur Membranes with Superior Properties
}

\author{
Jun Liu \\ Tianjin Polytechnic University, Tianjin 300160, China \\ Tel: 86-22-2452-8226 E-mail:sdliujun08@163.com
}

\begin{abstract}
Phase inversion via immersion precipitation was employed for PES tubular membrane preparation and using N,N-dimethylacetamide(DMAc) as solvent, PEG-400 as main constant additive. Through the experimental study we obtain a preparation process of PES tubular membrane with superior properties. Ethanol caused an increment in the flux at low coagulation bath temperature relative to the non-ethanol. And the low temperature of coagulation bath also improve membrane's rejection and its influence was most important. Other conditions included that the casting solution temperature must not be too high $\left(15^{\circ} \mathrm{C}\right.$ was best) and the membrane don't be exposed to atmosphere in long time. The prepared membrane under this condition shows excellent performance on flux and retention. Test results show that the flux can be up to $160 \mathrm{~L} \cdot \mathrm{m}^{-2} \mathrm{~h}^{-1}$ and the rejection can reach more than $97 \%$ (for ovalbvmin) under this condition. The flux was increased clearly compare to non-ethanol and high temperature.
\end{abstract}

Keywords: Membrane, Polyethersulfone, Ultrafiltartio, Additives

\section{Introduction}

Generally, polysulfone (PSF) and polyethersulfone (PES) are widely used for the preparation of microfiltration (MF), ultrafiltration (UF) and gas separation membranes. Besides,they are principally to the favorable characteristics of wide temperature limits, wide $\mathrm{pH}$ tolerances, fairly good chlorine resistance, easy to fabricate membranes in a wide variety of configurations and modules, wide range of pore sizes available for UF and MF applications ranging from $10 \AA$ to $0.2 \mathrm{um}$ and good chemical resistance to aliphatic hydrocarbons, alcohols and acids .

The common technique for the preparation of asymmetric ultrafiltration membranes is the phase inversion method. Membrane formation occurs in a very short time and involves a great number of elementary steps. However, more likely in some systems, a few or one mechanism is important, so it is worthwhile to look for some consisten correlation between a single parameter and the obtained membrane structure. Several researches have reported the eflfect of additives such as polyvinylpyrolidone(PVP)on the performance of an ultrafiltration membrane.This experiment was conducted to study the effect of additives such as PEG-400 and ethanol on the performance of membrane.

\section{Experimental Materials}

Polyethersulfone(Ultrason E6020P, $\mathrm{Mw}=58000 \mathrm{~g} / \mathrm{mol}$ ) provided by BASF Co(Germany). N,N-dimethylacetamide(DMAc) was purchased from Merck (Hohenbrunn, Germany). PEG was purchased from TiaJjin Chemical Reagent Co. The molecular weight Mw of PEG was $400 \mathrm{~g} / \mathrm{mol}$. Distilled water was used through the experiments. Ethanol was purchased from TianJin Chemical Reagent Co. Ultraviolet spectrophotometer was purchased from SHIMADZU Co.

\section{Preparation of Membranes}

Homogeneous solutions of the polymer dissolved in DM Ac were prepared using PEG additives by stirring and heating at $70^{\circ} \mathrm{C}$ until the solution is completely dissolved and homogeneous. The resultant polymer solution was kept in a glass bottle and air bubbles in the casting solutions were reduced by ultrasonification process for several hours. The solution was cast on support tube by machine at room temperature.

In order to guarantee a complete phase separation, the membrane was stored in the coagulation bath for $24 \mathrm{~h}$. This allows the water soluble components in the membrane to be leached out.

\section{Flux and Rejection}

The perform ances of the prepared membranes were characterized by using a cross flow system. All filtration experiments were carried out in a cross flow cell. The retentate was circulated by a centrifugal pump. The detail of the experimental set up is shown in Fig.1. Egg albumin was used as the feed for all vails. The retention of protein was investigated for prepared membranes by measuring the amount of protein in the permeate. The 
fluxes of each membrane were determined at $15 \mathrm{~min}$ with a transmembrane pressure of $0.1 \mathrm{MPa}$. The experiments were carried out at $25^{\circ} \mathrm{C}$.

The performance of the prepared membranes were characterized by using a cross flow system. The detail of the experimental set up is shown in Fig.1.

\section{Results and Discussions}

Fig. 1 shows pure water permeation of prepared membranes cast from $28 \mathrm{wt} \%$ PES, $51 \mathrm{wt} \%$ DMAc and $10 \mathrm{wt} \%$, $14 \mathrm{wt} \%, 18 \mathrm{wt} \%$ and $22 \mathrm{wt} \%$ PEG. The fluxes of each membrane were determined at $10 \mathrm{~min}$ with a transmembrane pressure of $0.1 \mathrm{MPa}$.

UF experimental data are summarized in Fig.1. Using PEG as additive, fluxes of each membrane increases from 47 to $167 \mathrm{l} / \mathrm{m}^{2} \mathrm{~h}^{-1}$ with an increase of ethanol concentration in the dope solution . the tubur membranes with the dope solution containing $0-25 \mathrm{wt} . \%$ ethanol concentration have a dense external surface and different pore sizes in internal surface.

With the coagulation bath temperature decrease, the flux decline obviously.And in the coagulation bath temperature $30 \sim 40^{\circ} \mathrm{C}$ the flux change greatly. But under $20^{\circ} \mathrm{C}$ the flux decline slowing. The coagulation bath temperature play an important role in all the factors of film forming.

From Fig.2, it is observed that the influence of different small molecule additive on membrane flux is significant. In the three additives, by adding $3 \%$ ethanol the flux obviously is the biggest, and the effect of adding acetone and lithium chloride is weak, which is far less obvious compare to adding ethanol. Coagulation bath at different temperatures show the same rules. The Fig.2 show that adding ethanol in the casting solution can increase the membrane flux.

The picture shows the effect of the ethanol and the coagulation bath temperature on membrane flux. In the diagram, the flux of ethanol is reduced as the additive increases, and the higher coagulation bath temperature increased, the more obvious. when the coagulation bath temperature is low, the effect on the flux is weak. At $11{ }^{\circ} \mathrm{C}$, the flux is almost the same and close to the membrane without ethanol. It is observed that the influence ethanol on membrane flux deceased with coagulation bath temperature decreasing.

The Fig.5 shows that the ethanol content decreased, the rejection rate of tubular membrane changed little. When ethanol content was higher than $3 \%$, the amount of retention was low obviously. This demonstrates that adding very small amounts of ethanol to casting solution don't make rejection rate to decline.

After adding ethanol, the membranes have a greater increase in flux and higher solute rejection as shown in Fig.5 and Fig.6. As ethanol is added to the dope solution, PWP of PES tubur membranes increases from 90 to 165 $\mathrm{L} /\left(\mathrm{m}^{2} \cdot \mathrm{h}^{1}\right)$.Ethanol also was used as additive to improve the separation performance of PES tubur membranes and compare with the separation performance of other non-ethanol. From the two picture, when the coagulation bath temperature was low (under $30^{\circ} \mathrm{C}$ ), the improvement result is more obvious.

\section{Conclusions}

Based on the above experimental results, the combining effects of low coagulation bath temperature and small molecule additives do make significant impact on membranese paration performance. At low coagulation bath temperature, PWP of PES tubur membranes has some decrease while it has the higher solute rejection. The addition of ethanol additive in the polymer solution has been shown to play an important method in the development of membrane performance with improved separation .

\section{References}

C. Barth, M.C. Goncalves, A.T.N. Pires, J. Roeder and B.A. Wolf. (2002). J. Membr. Sci., 169. (2002). 287-299.

H.T. Yeo, S.T. Lee, M.J. Han. (2000). Role of polymer additive in casting solution in preparation of phase inversion polysulfone membranes, J. Chem. Eng. Jpn. 33 (2000) 180.

M. Cheryan. (1998). Ultrafiltration and Microfiltration Handbook, Technomic Publishing Co., Lancaster, PA, 1998.

M. Wienk, R.M. Boom, M.A.M. Beerlage, A.M.W. Bulte, C.A. Smolders. (1996). Recent advances in the formation of phase inversion membranes made from amorphous or semi-crystalline polymers, J. Membr. Sci. 113 (1996) 361.

R.M. Boom, H.W. Reinders, H.H.W. Rolevink, Th. van den Boomgaard, C.A. Smolders. (1994). Equilibrium thermodynamics of a quaternary membrane-forming system with two polymers. I. Experiments, Macromolecules 27 (1994) 2041. 


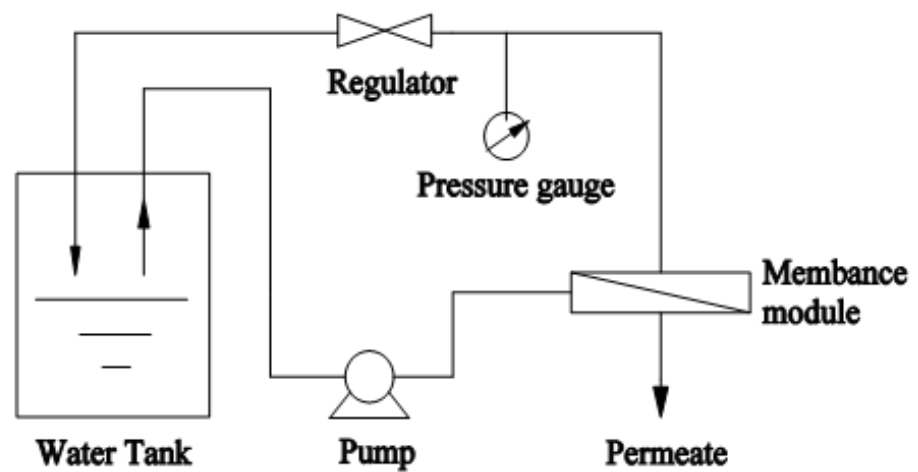

Figure 1. Flowchart of membrane testing

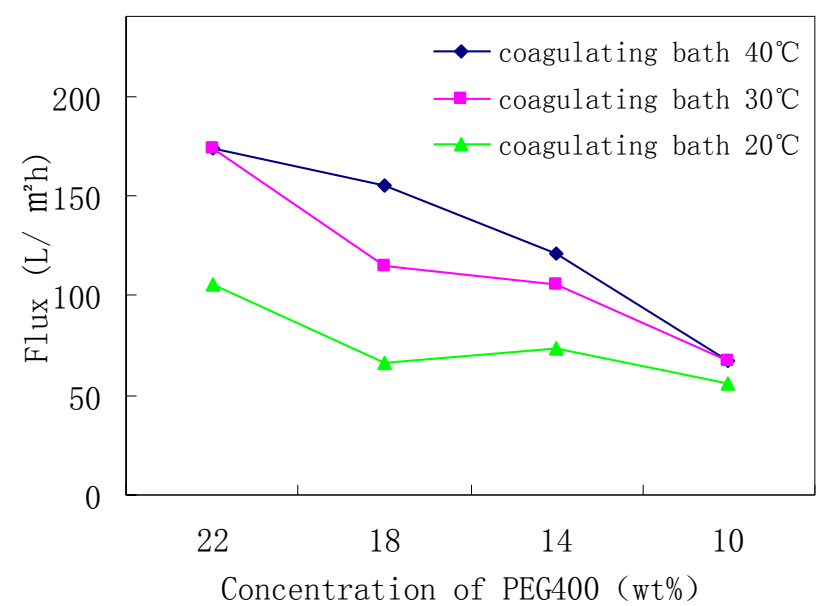

Figure 2. Effects of PEG concentration and coagulation bath temperature on pure water permeation flux

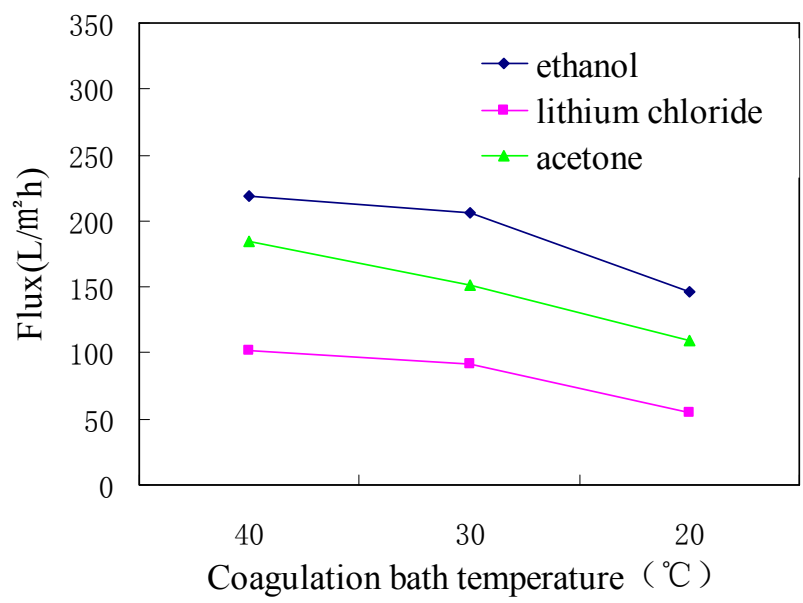

Figure 3. The effect of different small molecule additive on Flux 


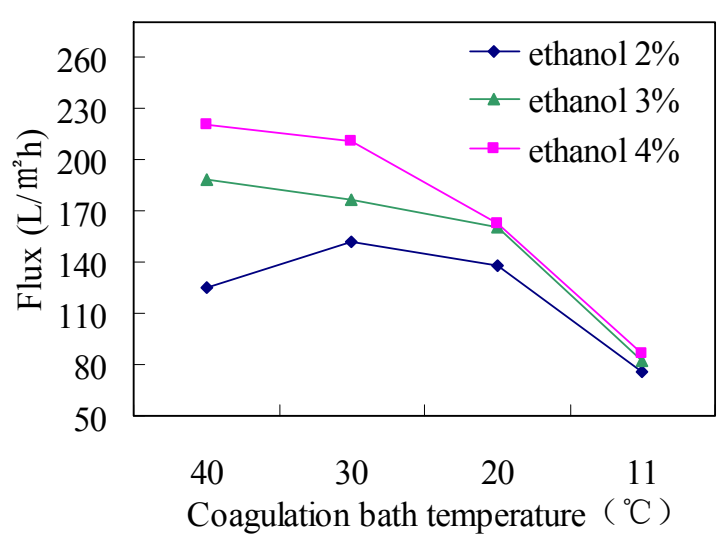

Figure 4. The effect of the ethanol and the coagulation bath temperature on membrane flux

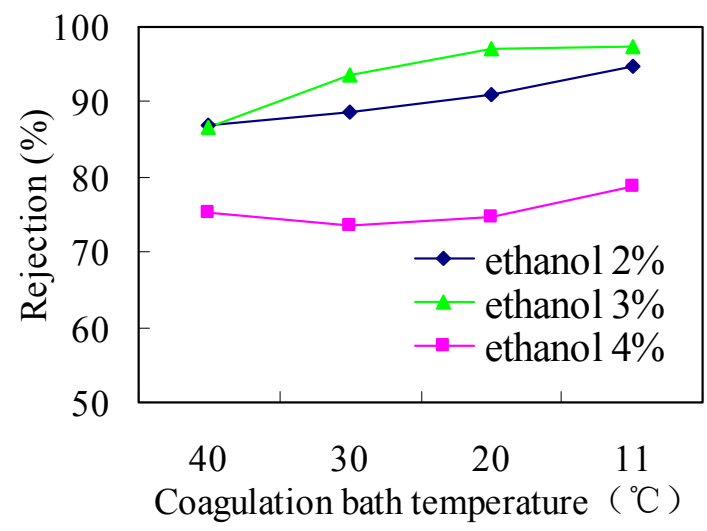

Figure 5. The effect of the ethanol and the coagulation bath temperature on membrane Rejection

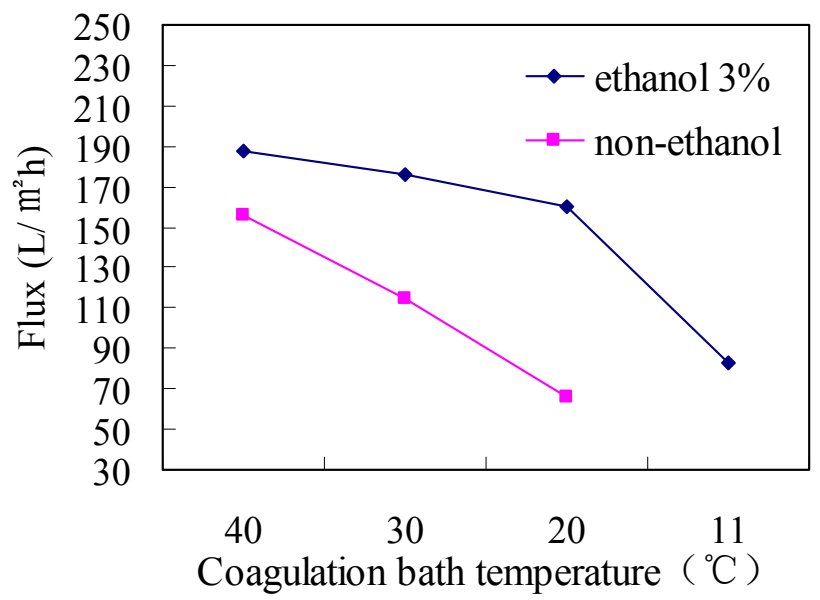

Figure 6. The change of membrane Flux with addition of ethanol 


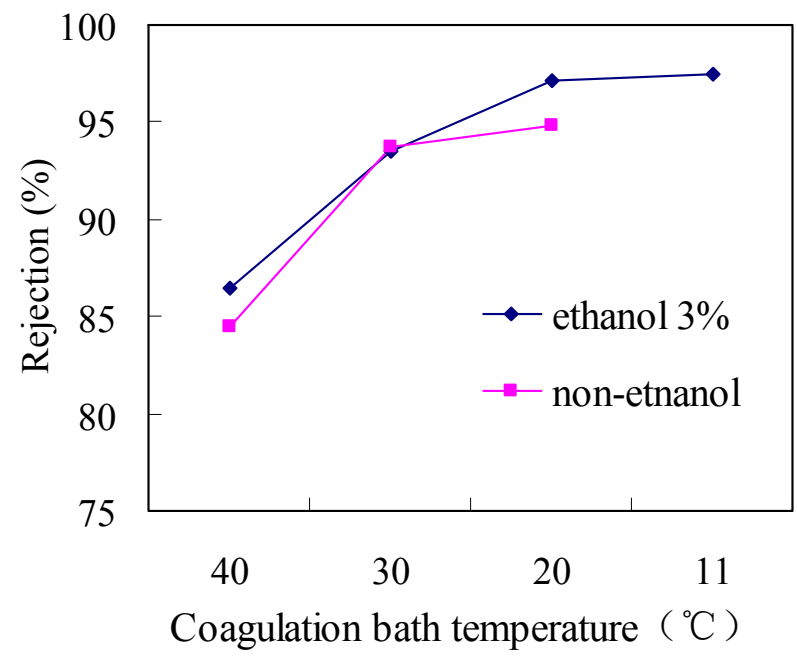

Figure 7. The change of membrane Rejection with addition of ethanol 